\title{
MINIMUM BED LENGTH TO OBTAIN "CONSTANT PATTERN" IN BI-COMPONENT FIXED-BED ADSORPTION
}

\author{
EIJI FURUYA AND YASUSHI TAKEUCHI \\ Department of Industrial Chemistry, Meiji University, Kawasaki 214
}

Key Words: Adsorption, Activated Carbon, Binary Component System, Constant Pattern Concept, Fixed Bed, Linear Driving Force, Minimum Bed Length, Monocarboxylic Acid, Monohydric Alcohol, Numerical Calculation

\begin{abstract}
A simple analytical solution is proposed to predict the minimum bed length, $Z_{\min }$, necessary to make two adsorption zones in bi-component fixed-bed adsorption separate from each other, by use of the so-called constant pattern concept and the linear driving force approximation. Values of $Z_{\min }$ obtained from the analytical solution were compared with those from numerical breakthrough curves based on a rather rigorous mass balance as well as diffusion equations. The solution was found to be accurate enough. Experiments were performed for two monohydric alcohols-activated carbon and two monocarboxylic acids-activated carbon systems, respectively. Comparison of the predicted $Z_{\min }$ based on the proposed equation gave larger values than the experimental values.
\end{abstract}

\section{Introduction}

To design a fixed-bed adsorber, breakthrough curves are not always necessary, and just a knowledge of the relationship between the break time and the bed length under certain operational conditions is enough. The relation will be a function of the length of the so-called adsorption zone.

For estimation of the adsorption zone length for single-component adsorption, Kawazoe and Fukuda proposed the so-called $(r-\zeta)$ method $^{6)}$ based on a linear-driving-force (LDF) approximation ${ }^{4)}$ and the constant pattern concept for the case of Langmuirtype isotherm systems and, later, Hashimoto and Miura $^{5)}$ presented a very similar method for Freundlich isotherm systems.

A rather rigorous numerical calculation of fixedbed breakthrough curves for non-linear isotherm systems was first proposed by $\mathrm{Carter}^{1,2)}$ for both single- and binary-component adsorption. He evaluated the resistance for intraparticle diffusion using differential mass balance equations and common fluid-to-particle rate equations. In the numerical calculation, finite difference equations were used. The authors used Carter's method to calculate breakthrough curves for single-component adsorption with Langmuir- and Freundlich-isotherm systems. ${ }^{3,10)}$ By use of the successive over-relaxation (SOR) method presented elsewhere, ${ }^{3,9)}$ the speed of convergence in the calculation became much higher. The authors' calculation procedure can be used in the calculation of binary component systems. In each iteration of the

Received June 8, 1985. Correspondence concerning this article should be addressed to Y. Taketichi calculation, adsorption equilibria can also be evaluated by use of the SOR method and thus the error in results become smaller than those with other numerical methods. In any case, the numerical solution will be useful for testing the validity of any simplified method.

On the other hand, the authors extended the constant pattern concept for single-component systems to multi-component systems and proposed a simple method to predict break times and the lengths of adsorption zones with respect to each component. ${ }^{12-14)}$ The calculation procedure for the breaktimes for respective components is presented elsewhere. ${ }^{13)}$ The method was proved to be useful in several cases. ${ }^{11-14)}$

In the present paper, a simple method is derived to estimate the minimum bed length, $Z_{\min }$, required for the establishment of two adsorption zones, using the same assumptions as did Miura et al. ${ }^{\text {) }}$ Then, the values of $Z_{\min }$ estimated were compared with those obtained from breakthrough curves calculated numerically for binary-component systems. Furthermore, a comparison of $Z_{\min }$ obtained by use of the simplified method with experimental results was performed for monohydric alcohols-activated carbon and monocarboxylic acids-activated carbon systems to show that the method gives a safe prediction.

\section{Development of Basic Equations}

Concentrations of solutes in the solid phase for binary-component adsorption on a fixed bed change with the time elapsed as shown in Fig. 1. Both components are adsorbed on the same portion of the bed, right after the operation starts (Fig. 1a), and 


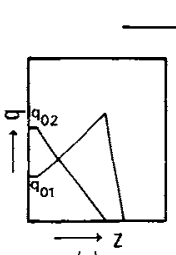

(a)

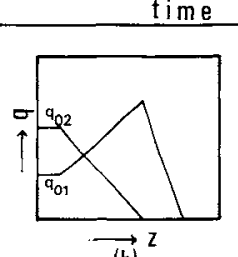

$\overrightarrow{(b)}^{2}$

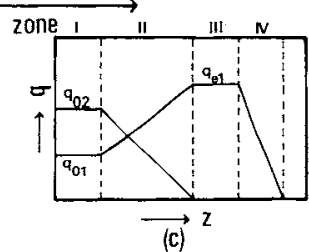

$\overrightarrow{(c)}^{2}$
Fig. 1. Schematic history of amount adsorbed in a fixed bed and classification of four zones. I, second equilibriumattained zone; II, second adsorption zone; III, first equilibrium-attained zone; IV, first adsorption zone.

afterwards each adsorption zone is established (Fig. 1b). Next, the two adsorption zones separate from each other with the progress of time and then become constant in length (Fig. 1c). From the mass balance for less-adsorbable and more-adsorbable components (component 1 and 2), respectively, under the constant pattern.condition, the exhausion time for component $1, t_{E 1}$, is described by Eq. (1) in the same way as in the authors' previous paper. ${ }^{13)}$

$$
\begin{gathered}
t_{E 1}=\frac{c_{e}\left\{z+(1 / 2) Z_{\mathrm{IV}}\right\}}{U_{1} c_{01}+\left\{1-\left(q_{01} / q_{e}\right)\right\} U_{2} c_{e}} \\
U_{1}=u c_{e} / \gamma q_{e}, \quad U_{2}=u c_{02} / \gamma q_{02} \\
z=Z_{\mathrm{I}}+Z_{\mathrm{II}}+Z_{\mathrm{III}} \quad \text { at } \quad t=t_{E 1}
\end{gathered}
$$

where $u$ and $\gamma$ denote linear flow rate of fluid and bulk density of the fixed bed, $q_{01}$ and $q_{02}$ are amount adsorbed of components 1 and 2, respectively, in equilibrium with $c_{01}$ and $c_{02}, q_{e}$ is the amount adsorbed in equilibrium with the maximum concentration $c_{e}$ of component 1, i.e., the concentration of equilibrium-attained zone $\left(Z_{\mathrm{III}}\right), z$ denotes the whole bed length and $Z_{\mathrm{IV}}$ corresponds to the length of the first adsorption zone, and $U_{1}$ and $U_{2}$ denote travelling velocities of the first and the second adsorption zones, respectively.

The break time of component $2, t_{B 2}$, is given as follows from the mass balance for component $2 .{ }^{13)}$

$$
\begin{gathered}
t_{B 2}=\frac{z-(1 / 2) Z_{\mathrm{II}}}{U_{2}} \\
z=Z_{\mathrm{I}}+Z_{\mathrm{II}} \quad \text { at } \quad t=t_{B 2}
\end{gathered}
$$

Therefore, the difference between the exhaustion time and the break time, $\Delta t\left(=t_{B 2}-t_{E 1}\right)$, can be written as:

$$
\begin{aligned}
\Delta t= & {\left[\frac{1}{U_{2}}-\frac{c_{e}}{U_{1} c_{01}+\left\{1-\left(q_{01} / q_{e}\right)\right\} U_{2} c_{e}}\right] z } \\
& -\frac{1}{2}\left[\frac{Z_{\mathrm{II}}}{U_{2}}+\frac{c_{e} Z_{\mathrm{IV}}}{U_{1} c_{01}+\left\{1-\left(q_{01} / q_{e}\right)\right\} U_{2} c_{e}}\right]
\end{aligned}
$$

It is clear from the equation that the difference, $\Delta t$, is a function of bed length $z$ under the condition that a constant pattern is established. When the value of $z$ is the same as the minimum bed length $Z_{\min }$, required for the separation of Zone IV from Zone II, $\Delta t$ should be equal to zero. Therefore, replacing the left-hand side of Eq. (3) with $0, Z_{\text {min }}$ can be given as follows:

$$
Z_{\min }=\frac{1}{2}\left[\frac{U_{2} c_{e}}{U_{1} c_{01}-\left(q_{01} / q_{e}\right) U_{2} c_{e}}\left(Z_{\mathrm{II}}+Z_{\mathrm{IV}}\right)+Z_{\mathrm{II}}\right]
$$

The amount adsorbed, $q_{01}$ and $q_{02}$, can be estimated from adsorption equilibria for a binary system and for given concentrations, $c_{01}$ and $c_{02}$, respectively. The equilibrium amount adsorbed of component 1 $\left(q_{e}\right)$ for concentration $\left(c_{e}\right)$ at Zone II, can be also estimated as described elsewhere. ${ }^{8,11,13)}$ The length of $Z_{\mathrm{IV}}$ can easily be given by use of well-known procedures ${ }^{3,5,6,10)}$ for a single-component system with the values of $c_{e}$ and $q_{e}$, and $Z_{\mathrm{II}}$ can be estimated from an apparent adsorption isotherm as described elsewhere. ${ }^{13)}$ Therefore, all of the variables on the righthand side of Eq. (4) are known.

\section{Determination of Minimum Bed Length from Breakthrough Curves}

For numerical calculation of breakthrough curves for binary adsorption on a fixed bed, the calculation procedure is essentially similar to that for single component systems. As is well known, dimensionless equations of fixed-bed adsorption for component $i$ (where $i=1$ or 2) can be written as Eqs. (5) to (8) by use of the assumptions of plug flow, constant influent flow rate, surface diffusion controlling, and establishment of adsorption equilibrium momentarily at the particle-to-fluid interface.

Material balance in the bed:

$$
\frac{\partial \bar{C}_{i}}{\partial Z_{i}}+\frac{\partial \bar{Q}_{i}}{\partial T_{i}}=0
$$

Rate equations

for fluid film transfer:

$$
\frac{\partial \bar{Q}_{i}}{\partial T_{i}}=\bar{C}_{i}-C_{s, i}
$$

for transfer at interface:

$$
\frac{\partial \bar{Q}_{i}}{\partial T_{i}}=-\left(N_{s} K_{0}\right)_{i}\left(\frac{\partial Q_{i}}{\partial R}\right)_{R=1}
$$

for intraparticle diffusion:

$$
\frac{\partial Q_{i}}{\partial T_{i}}=\frac{\left(N_{s} K_{0}\right)_{i}}{3}\left(\frac{\partial^{2} Q_{i}}{\partial R^{2}}+\frac{2}{R} \frac{\partial Q_{i}}{\partial R}\right)
$$

where $C_{i}$ denotes fluid concentration of component $i$, $Q_{i}$ is the amount adsorbed of component $i . Z_{i}$ and $T_{i}$ are respectively bed length and contact time regarding component $i, R$ means radial length in a particle, and $N_{S} K_{0}\left(=k_{F} a_{v} / \beta k_{S} a_{v}\right)$ is the diffusional parameter.

As for the adsorption equilibria, isotherms for the 
respective single-component adsorption were assumed to obey Freundlich-type equation.

$$
q_{i}=k_{i} c_{i}^{1 / n_{i}}
$$

Solving simultaneously Eqs. (5) to (8) by using adsorption equilibria, breakthrough curves were calculated. The SOR method ${ }^{3,9)}$ was used for various calculation conditions. Since the values of $k_{F} a_{v}$ were estimated to be $0.1 \mathrm{~s}^{-1}$ from Wilson's equation ${ }^{15)}$ and the experimentally observed values of $k_{S} a_{v}$ were almost $0.1 \mathrm{~g} / \mathrm{cm}^{3} \mathrm{~s}$ for the butyric acid-valeric acidactivated carbon system, the values of $k_{F} a_{v}$ and $k_{S} a_{v}$, adopted in the calculation were $0.05,0.1$ and 0.2 in respective units. The values of the equilibrium parameters, $k$ and $1 / n$, changed from 2 to 7 and from $1 / 2$ to $1 / 4$, respectively, when the unit of amount adsorbed was expressed in tems of $\mathrm{mmol} / \mathrm{g}$ and that of fluid concentration in tems of $\mathrm{mmol} / \mathrm{l}$.

Figure 2 shows some examples of breakthrough curves calculated by use of the numerical method including Eq. (8) (i.e., neither LDF approximation nor the so-called constant pattern concept was used).

It is obvious that a bed length of $5.5 \mathrm{~cm}$ is not enough to make Zones II and IV separate from each other. The results for bed lengths of 25.5 and $45.5 \mathrm{~cm}$ show that the maximum concentration of component 1 reaches $c_{e}$. As shown in Fig. 2, $\Delta t$ can be obtained from numerical breakthrough curves for the respective bed lengths.

From the values of $\Delta t$ with respect to various operational conditions, $Z_{\min }$ values were calculated as shown in Fig. 3 and some of the results are listed in Table 1. It seems that the value of minimum bed length required to make Zone II and Zone IV separate from each other is dependent on the travelling velocities of the two zones, $U_{1}$ and $U_{2}$, as well as the lengths of the zones, $Z_{\mathrm{II}}$ and $Z_{\mathrm{IV}}$. The results can also be estimated from Eq. (4).

\section{Comparison of $Z_{\min }$ from Numerical Results with Those from the Simplified Method}

When the second term in brackets of the right-hand side of Eq. (4) is negligible, the ratio of $Z_{\min }$ to $\left(Z_{\mathrm{II}}+Z_{\mathrm{IV}}\right)$ is dependent on the ratio of travelling velocities, $U_{2} / U_{1}$. Therefore, values of $Z_{\min } /$ $\left(Z_{\mathrm{II}}+Z_{\mathrm{IV}}\right)$ and $U_{2} / U_{1}$ were evaluated from the values presented in Table 1 and are listed in columns 6 and 7 of the table.

With respect to various equilibria parameters and diffusional resistance within the particles for realistic cases, $Z_{\mathrm{II}}$ and $Z_{\mathrm{IV}}$ were determined by use of the procedures mentioned above and then $Z_{\min }$ was obtained from Eq. (4). Furthermore, these values were also obtained from the numerical breakthrough curves. The ratios of $Z_{\min }$ to $\left(Z_{\mathrm{II}}+Z_{\mathrm{IV}}\right)$ are plotted in Fig. 4 against the ratio of travelling velocities, $U_{2} / U_{1}$.

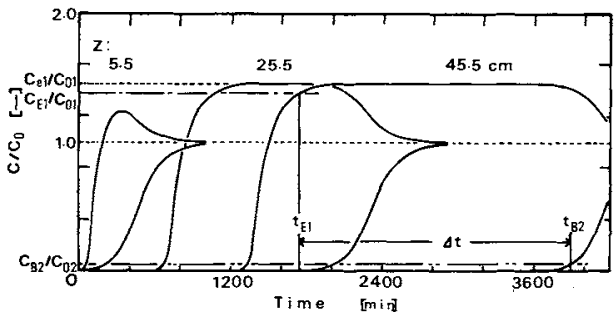

Fig. 2. Numerical breakthrough curves.

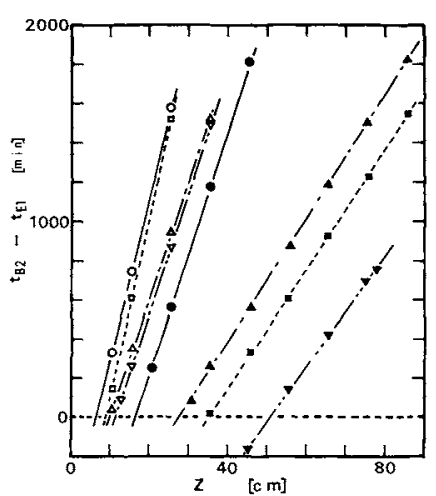

Fig. 3. Plots of $\left(t_{B 2}-t_{E 1}\right)$ from numerical breakthrough curves versus bed length $z$. (Keys refer to Table 1.)

Figure 4 shows that the relations between the values of $Z_{\mathrm{min}} /\left(Z_{\mathrm{II}}+Z_{\mathrm{IV}}\right)$ and the values of $U_{2} / U_{1}$ from the simplified method and from the numerical breakthrough curves can be expressed by a single curve irrespective of the values of equilibrium parameter, because the effect of the equilibrium is included in the ratio $U_{2} / U_{1}$.

\section{Application of the Simplified Method to Practical Cases}

For adsorption from binary monocarboxylic acid solution and binary monohydric alcohol solutions on a fixed bed of carbon particles, experiments were performed at $25^{\circ} \mathrm{C}$ for various bed lengths.

Since the experimental procedure is almost the same as that described elsewhere, ${ }^{13)}$ only the results are presented here. Experimental breakthrough curves are shown in Fig. 5 for the system butyric acid-valeric acid-activated carbon. It seems from the figure that the breakthrough curves with respect to the 43.3 and $61.3 \mathrm{~cm}$ long beds, respectively, can be used to evaluate $Z_{\min }$.

The difference, $\Delta t$ (see Fig. 2), between the exhaustion time $t_{E 1}$ and the break time $t_{B 2}$, which correspond to $c_{E 1}=0.9 c_{e}$ and $c_{B 2}=0.1 c_{02}$, respectively, is plotted against bed length, $z$, as shown in Fig. 6. Also shown in the figure are the results for other monocarboxylic acid systems. For monohydric alcohol systems, the results are shown in Fig. 7.

The values of $Z_{\min }$ obtained from Figs. 6 and 7 are 
Table 1. Minimum bed length $Z_{\min }$ obtained from numerical breakthrough curves

\begin{tabular}{|c|c|c|c|c|c|c|c|}
\hline $\begin{array}{l}\text { Keys in } \\
\text { Fig. } 3\end{array}$ & $U_{1}$ & {$[\mathrm{~cm} / \mathrm{h}]$} & $Z_{\mathrm{II}}$ & {$[\mathrm{cm}]$} & $\begin{array}{l}Z_{\min } \\
{[\mathrm{cm}]}\end{array}$ & $\begin{array}{l}U_{2} / U_{1} \\
{[-]}\end{array}$ & $\begin{array}{c}Z_{\min } /\left(Z_{11}+Z_{1 V}\right) \\
{[-]}\end{array}$ \\
\hline 0 & 1.75 & 0.505 & 11.8 & 5.8 & 6.5 & 0.289 & 0.369 \\
\hline$\Delta$ & 1.83 & 0.651 & 12.0 & 7.5 & 10.0 & 0.356 & 0.513 \\
\hline$\square$ & 0.941 & 0.385 & 7.5 & 6.9 & 9.0 & 0.409 & 0.625 \\
\hline $\bar{\nabla}$ & 1.27 & 0.548 & 9.1 & 8.5 & 11.5 & 0.432 & 0.653 \\
\hline - & 0.791 & 0.430 & 6.6 & 11.3 & 16.5 & 0.543 & 0.922 \\
\hline$\Delta$ & 1.33 & 0.780 & 9.5 & 17.2 & 27.5 & 0.584 & 1.030 \\
\hline $\bar{a}$ & 1.02 & 0.661 & 7.7 & 19.9 & 35.0 & 0.645 & 1.268 \\
\hline$\nabla$ & 0.693 & 0.508 & 6.2 & 22.3 & 50.5 & 0.733 & 1.772 \\
\hline
\end{tabular}

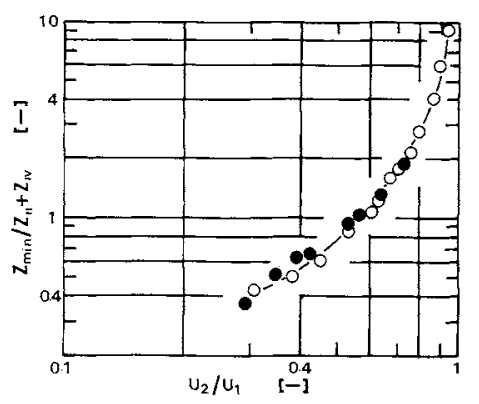

Fig. 4. $Z_{\min } /\left(Z_{\mathrm{II}}+Z_{\mathrm{IV}}\right)$ versus ratio of travelling velocities, $U_{2} / U_{1}$. $\bigcirc$, from simplified method; $\bullet$, from numerical breakthrough curves.

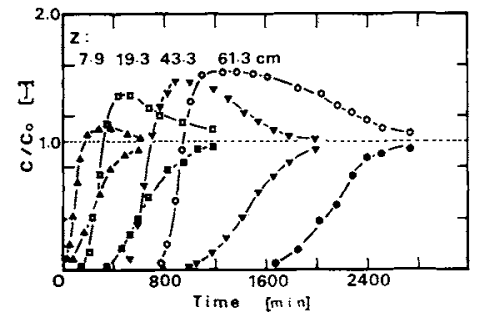

Fig. 5. Experimental breakthrough curves for butyric acid valeric acid system.

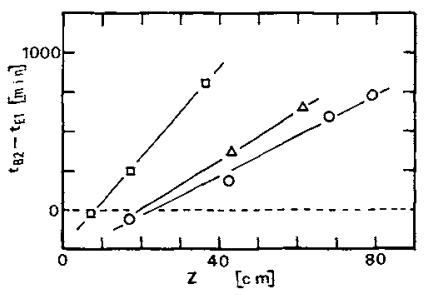

Fig. 6. $\Delta t\left(=t_{B 2}-t_{E 1}\right)$ from experimental results versus bed length $z$ for monocarboxylic acid systems. (Keys refer to Table 2.)

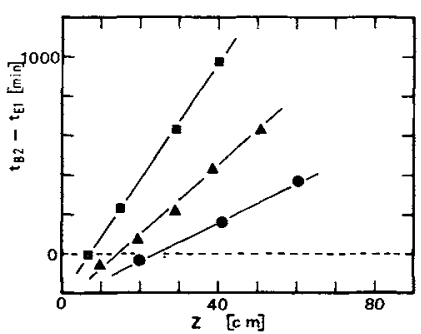

Fig. 7. $\Delta t\left(=t_{B 2}-t_{E 1}\right)$ from experimental results versus bed length $z$ for monohydric alcohol systems. (Keys refer to Table 2.)
Table 2. Minimum bed length for monocarboxylic acid and for monohydric alcohol systems

\begin{tabular}{|c|c|c|c|c|c|}
\hline \multirow{2}{*}{$\begin{array}{c}\text { Keys in } \\
\text { Figs. } 6 \\
\text { and } 7 \\
0\end{array}$} & \multicolumn{2}{|c|}{ System } & \multicolumn{2}{|c|}{$\begin{array}{l}Z_{\min }[\mathrm{cm}] \\
\text { Obšerved Estimated }\end{array}$} & \multirow{2}{*}{$\left.\begin{array}{c}U_{2} / U_{1} \\
{[-]}\end{array}\right]$} \\
\hline & Propionic ac & d-butyric acid & 22.7 & 24.3 & \\
\hline$\square$ & Propionic ac & d-valeric acid & 8.5 & 13.2 & 0.25 \\
\hline$\triangle$ & Butyric acid & - valeric acid & 20.1 & 27.1 & 0.61 \\
\hline 0 & $n$-Propanol & -n-butanol & 23.8 & 38.4 & 0.87 \\
\hline $\mathbf{0}$ & n-Propanol & $-n$-pentanol & 7.9 & 11.5 & 0.88 \\
\hline$\Delta$ & $n$-Butanol & -n-pentanol & 14.8 & 21.9 & 0.87 \\
\hline
\end{tabular}

listed in Table 2 as $Z_{\text {minobs. }}$ along with those estimated by use of Eq. (4), expressed as $Z_{\min \text { esti. }}$. An error in estimation of $Z_{\min }$ by the simplified method, which included all estimation errors of $Z_{\mathrm{II}}, Z_{\mathrm{IV}}$ and equilibrium amount adsorbed for binary system, was found to be about $35 \%$, except for the propionic acidbutyric acid system. In this case, although adsorption zones II and IV separate from each other they seem not to be constant in length.

The values obtained from Eq. (4), however, were larger than the experimental values for almost all systems studied. Therefore, it can be concluded that this simple method gives a safe prediction of minimum bed length.

\section{Conclusion}

For binary component systems, the minimum bed length required for separation of each adsorption zone, $Z_{\min }$, was calculated with the aid of the constant pattern concept and linear-driving-force approximation. The results obtained agreed fairly well with those determined from the numerical breakthrough curves based on rather rigorous differential equations. From comparison of both results with experimental results for the systems monocarboxylic acid-activated carbon and monohydric alcohol-activated carbon, it became clear that the above simple procedure gave a safe prediction of the minimum bed length required to achieve separation of two adsorption zones in the fixed bed. 


\section{Acknowledgment}

The authors would like to express their thanks to Mr. Y. Suzuki and Mr. T. Motomura for their assistance in experimental work.

They are also grateful to the Computation Center, Meiji University, for assisting them in computational work.

A part of this study was supported by a Grant-in-Aid for Scientific Research (No. 56470093) from the Ministry of Education, Science and Culture of Japan.

\section{Nomenclature}

$b \quad=$ mean particle radius $[\mathrm{m}]$

C $=c / c_{0} \quad[-]$

c $=$ fluid concentration $\quad\left[\mathrm{kg} / \mathrm{m}^{3}\right]$

$c_{B} \quad=$ fluid concentration at break-point $\quad\left[\mathrm{kg} / \mathrm{m}^{3}\right]$

$c_{E} \quad=$ fluid concentration at exhaustion-point $\quad\left[\mathrm{kg} / \mathrm{m}^{3}\right]$

$c_{e} \quad=$ maximum concentration of less-adsorbable component $\quad\left[\mathrm{kg} / \mathrm{m}^{3}\right]$

$c_{0 i} \quad=$ initial concentration of component $i \quad\left[\mathrm{~kg} / \mathrm{m}^{3}\right]$

$k_{F} a_{v} \quad=$ fluid-film volumetric mass transfer coefficient

$k_{S} a_{v} \quad=$ intraparticle volumetric mass transfer coefficient

$N_{S} K_{0} \quad=\beta k_{\mathrm{S}} a_{v} / 5 k_{\mathrm{F}} a_{v} \quad[-]$

$1 / n=$ Frendlich exponent $\quad[-]$

$\bar{Q} \quad=$ mean value of $q / q_{0}$ [-]

$Q \quad=$ local value of $q / q_{0}$ within particles $\quad[-]$

$q \quad=$ amount adsorbed in equilibrium with $c \quad[\mathrm{~kg} / \mathrm{kg}]$

$q_{e} \quad=$ amount adsorbed in equilibrium with $c_{e}$ for single-component system

qoi $=$ amount adsorbed in equilibrium with $c_{0 i}$ for binary-component system $\quad[\mathrm{kg} / \mathrm{kg}]$

$=r / b$

$=$ radial length

$=(t-z \varepsilon / u) k_{F} a_{v} / \beta \gamma$

$=$ time

$[\mathrm{kg} / \mathrm{kg}]$

= break time for more-adsorbable component, corresponding to $c_{B 2}=0.1 c_{02}$

$=$ exhaustion time for less-adsorbable component, corresponding to $c_{E 1}=0.9 c_{e}$

$=$ refer to Eq. (3) and Fig. 2

$=$ travelling velocity of adsorption zone

= linear flow rate

$=z k_{F} a_{v} / u$ $\begin{array}{lll}z & =\text { bed length } \quad[\mathrm{m}] \\ Z & =\text { minimum bed length required for establishment }\end{array}$

$Z_{\text {min }}=$ minimum bed length required for establishment

$Z_{\mathrm{II}} \quad=$ length of second adsorption zone $\quad[\mathrm{m}]$

$Z_{\mathrm{IV}} \quad=$ length of first adsorption zone [m]

$\beta \quad=$ slope af, operational line $\quad\left[\mathrm{m}^{3} / \mathrm{kg}\right]$

$\gamma \quad=$ bed bulk density $\quad\left[\mathrm{kg} / \mathrm{m}^{3}\right]$

〈Subscript〉

$i \quad=$ component

\section{Literature Cited}

1) Carter, J. W.: Trans. Instn. Chem. Engrs., 44, T253 (1966).

2) Carter, J. W. and H. Husain: Trans. Instn. Chem. Engrs., 50, 69 (1972).

3) Furuya, E. and Y. Takeuchi: Research Report of the Faculty of Engineering, Meiji Univ., No. 35, 95 (1978).

4) Garg, D. R. and D. M. Ruthven: $A I C h E J ., 21,200$ (1975).

5) Hashimoto, K., K. Miura and M. Tsukano: J. Chem. Eng. Japan, 10, 26 (1977).

6) Kawazoe, K. and Y. Fukuda: Kagaku Kōgaku, 29, 374 (1965).

7) Miura, K., H. Kurahashi, Y. Inokuchi and K. Hashimoto: J. Chem. Eng. Japan, 12, 281 (1979).

8) Radke, C. I. and J. M. Prausnitz: AIChE J., 18, 761 (1972).

9) Smith, G. D.: "Numerical Solution of Partial Differential Equations," Oxford Univ. Press (1965).

10) Takeuchi, Y. and E. Furuya: J. Chem. Eng. Japan, 13, 500 (1980).

11) Takeuchi, Y., E. Furuya and Y. Suzuki: Kyogyo Yosui, No. 233, 30 (1978).

12). Takeuchi, Y., Y. Suzuki and E. Furuya: J. Chem. Eng. Japan, 12, 486 (1979).

13) Takeuchi, Y., T. Wasai and S. Suginaka: J. Chem. Eng. Japan, 11, 458 (1978).

14) Takeuchi, Y. et al.: "Studies on the Variation of Effluent Water Quality from School and Research Laboratories and on the Physico-Chemical Treatment of the Water," Report of the Institute of Science and Technology Special Project No. 4, Meiji Univ. (March 31, 1984).

15) Wilson, E. J. and C. J. Geankoplis: Ind. Eng. Chem. Fundam., $5,9(1966)$. 